\title{
Typology of the flow structure in dividing open channel flows
}

\author{
ADRIEN MOMPLOT ${ }^{1}$, GISLAIN LIPEME KOUYI ${ }^{1}$, EMMANUEL MIGNOT $^{2}$, NICOLAS \\ RIVIERE $^{2}$, JEAN-LUC BERTRAND-KRAJEWSKI ${ }^{1}$ \\ ${ }^{1}$ Université de Lyon, INSA de Lyon, LGCIE - Laboratory of Civil \& Environnemental Engineering, \\ F-69621 Villeurbanne cedex, FR Emails: adrien.momplot@insa-lyon.fr (Corresponding Author); \\ gislain.lipeme-kouyi@insa-lyon.fr; jean-luc.bertrand-krajewski@insa-lyon.fr \\ ${ }^{2}$ LMFA, CNRS-Université de Lyon, INSA de Lyon, Bât. Joseph Jacquard, 20 Avenue Albert Einstein, \\ F-69621 Villeurbanne cedex, FR Emails: emmanuel.mignot@insa-lyon.fr; nicolas.riviere@insa-lyon.fr
}

\section{ABSTRACT}

The present study reports the occurrence of a new recirculation structure taking place in the lateral branch of a $90^{\circ}$ bifurcation flow. This recirculation structure is "helix-shaped" and strongly differs from the typical "closed" recirculation often reported in the literature. The aim of the study is to detail their characteristics using experimental and numerical approaches and to establish a typology, i.e. the flow conditions leading to each recirculation structure based on the upstream Froude number and the upstream aspect ratio.

Keywords: bifurcation, hydraulic parameters, open-channel flow, RANS model, recirculation structures

\section{Introduction}

Bifurcations of open-channel flows are specific structures frequently encountered in sewer systems or river delta. Bifurcation flows have been widely studied (Grace and Priest, 1958; Shettar and Murthy, 1996; Hsu et al., 2002; Ramamurthy et al., 2007; Mignot et al., 2013; Momplot et al., 2013). Hence, governing parameters of a bifurcation flows are well identified: inlet discharge and discharge repartition in downstream channels. In the literature, the principal challenge for bifurcations lies in the prediction of the flow distribution from the incoming flow towards each outgoing flow. A review of analytical models developed to access such prediction can be found in Rivière et al. $(2007,2011)$. The model proposed by the authors is based on the momentum conservation law as proposed by Ramamurthy et al. (1990), suitable stage-discharge relationships for the downstream controls in the outflow channels and an empirical correlation obtained through experimental data.

Nevertheless, understanding the behavior of the flow structures within the bifurcation is also important, as they strongly impact pollutant or sediment transport and mixing 
processes. The general pattern of a steady subcritical 3-branch bifurcation is described by Neary et al. (1999). A three-dimensional recirculating region develops in the lateral branch and secondary flows appear in both outlets. Mignot et al. (2014) detailed the mixing layer taking place at the frontier between the main flow and the recirculation zone in the lateral branch. Recirculation zones, also defined as bubbles, are encountered in various geometries as listed by Li and Djilali (1995).

Regarding specifically the recirculation zone, authors such as Kasthuri and Pundarikanthan (1987), Shettar and Murthy (1996) and Neary et al. (1999) sketch the recirculation zone (in top view) as a closed semi-elliptic region developing along the upstream wall of the lateral branch with maximum length and width at the free-surface and minimum extensions in the near-bed region. Kasthuri and Pundarikanthan (1987) and Shettar and Murthy (1996) respectively measure and compute the free-surface length and width of this recirculation zone. The authors agree that as the relative lateral discharge increases, the dimensions of the recirculation zone decreases. Neary et al. (1999) then compute flow configurations with varying channel width ratios and dimensionless water depths and exhibit varying characteristics of the recirculation zone pattern without clear explanation of the different types of recirculation zones.

The aim of the present paper is twofold: first to describe the two main flow structures that can be observed in the lateral branch of a $90^{\circ}$ bifurcation and second to determine the flow conditions for which each structure is observed. The paper is organized as follows: after presenting the experimental and numerical approaches, the characteristics of the different types of recirculation zones are described based on two measured and computed flows (F1 and F2) and finally a campaign of numerical simulations (including 16 different cases) is led in order to establish the flow typology.

\section{Material and methods}

\subsection{Experimental set up}

The experimental set-up (see Fig. 1) is a horizontal 3-branch equal width $(B=30 \mathrm{~cm})$ glass open-channel bifurcation of 2 and 2.6 meters long channels for the inlet and both outlet respectively. Boundary conditions are the inlet discharge $Q_{U}$ (measured by a flow-meter in the pumping loop) and the weir crest height $C_{D}$ and $C_{L}$ at the downstream end of each of the two outlet channels. The water depths in the upstream, lateral and downstream branches are defined as $h_{U}, h_{L}$ and $h_{D}$ respectively and are measured using a digital point gauge. The discharge distribution $Q_{L} / Q_{U}$ in the bifurcation is measured through an additional flow-meter in the pumping loop. In the studied cases, flow conditions are sub-critical everywhere. Details about this set-up are available in Mignot et al. (2013 and 2014). 


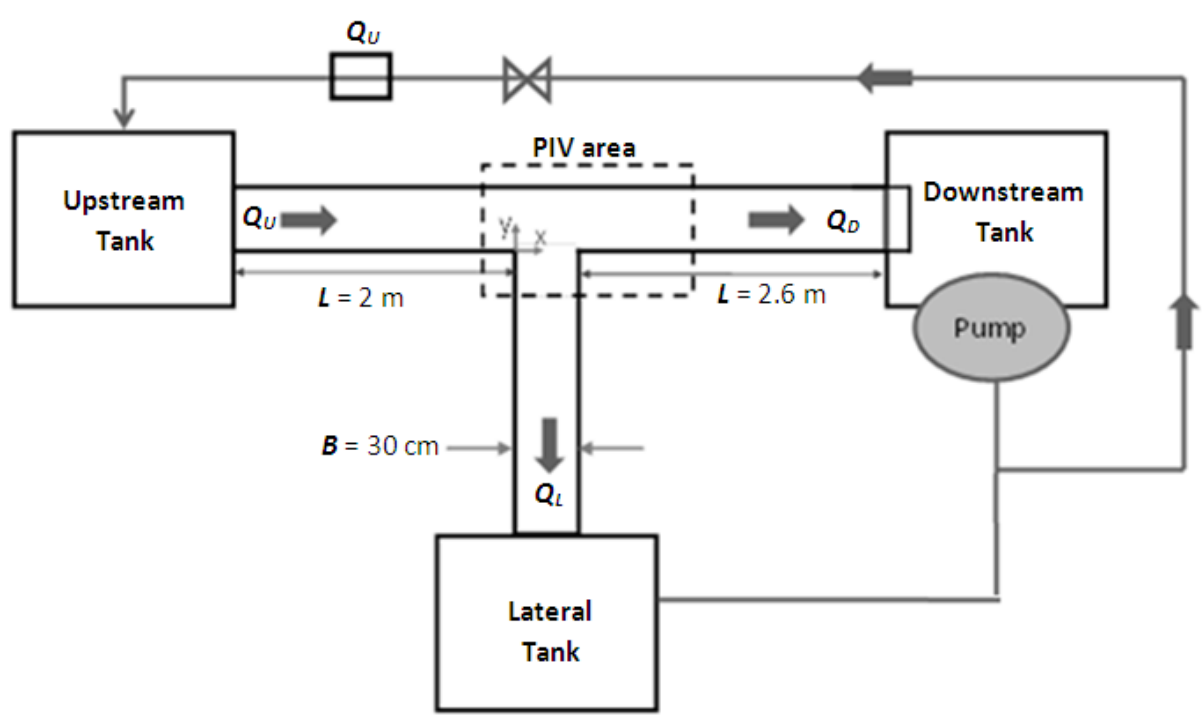

Figure 1. Experimental set up used for flow validation.

\subsection{Modelling strategy}

Numerical simulations are performed under the commercial software ANSYS Fluent version 14.0, following the modelling strategy proposed by Momplot et al. (2013) for computing bifurcation flow F0 (see Table 1), these simulations are confronted with PIV measurements of the horizontal velocity fields (see Fig. 2). Overall performances are fair. Additionally, simulated discharge repartition and measured discharge repartition shows fair agreement (differences are less than $10 \%$ ).

Table 1. Characteristics of the validated flow.

\begin{tabular}{cccccc}
\hline \hline Flow id. & $\begin{array}{c}\text { Inlet } \\
\text { discharge } Q_{U} \\
\left(\text { L.s }{ }^{-1}\right)\end{array}$ & $\begin{array}{c}\text { Weir crest } \\
\text { height } \\
h_{\text {crest }}(\mathrm{m})\end{array}$ & $\begin{array}{c}\text { Discharge } \\
\text { distribution } \\
\left(Q_{L} / Q_{U}\right)\end{array}$ & $\begin{array}{c}\text { Froude } \\
\text { Number in } \\
\text { upstream } \\
\text { channel }(-)\end{array}$ & $\begin{array}{c}\text { Upstream } \\
\text { aspect ratio } \\
B / h_{U}(-)\end{array}$ \\
\hline \hline F0 & 4 & 0.12 & 0.51 & 0.102 & 2.5 \\
\hline \hline
\end{tabular}

81

The model solves the RANS (Reynolds Averaged Navier-Stokes) equations using the Volume of Fluid - VOF -method for computing the free-surface curve and a Reynolds stress model - RSM - as turbulence model for system closure (see Launder et al., 1975). Scalable wall-functions (see Grotjans and Menter, 1998) are used for walls; a uniform velocity $U_{\text {Inlet }}$ is set at the inlet cross-section; atmospheric pressure $P_{0}$ is set at the top of the computational domain and at outlets. Crest heights are explicitly represented in the mesh. After the weirs, standard pressure outlet conditions are set. Discretisation scheme use for pressure is BodyForce Weighted and Second-Order Upwind for other variables. Pressure-velocity coupling algorithm is PISO. 

Roache (1994) as:

$$
G C I_{X}=\frac{\left(X_{F}-X_{C}\right) \cdot r^{p}}{r^{p}-1}
$$

With : $-G C I_{X}$ : the simulation error on variable $X$ due to the fine mesh (dimension of $X), X$ can be a discharge, a water depth, a velocity, etc.

$-X_{F}$ : the simulated variable $X$ for the fine mesh (dimension of $X$ )

$-X_{C}$ : the simulated variable $X$ for the coarse mesh (dimension of $X$ )

$-r$ : the ratio $\frac{N_{F}}{N_{C}}, N_{F}$ being the fine mesh number of cells and $N_{C}$ the coarse mesh number of cells (dimensionless)

$-p$ : the discretisation schemes order (dimensionless).

The $G C I_{X}$ value is an estimator of the error committed on the true variable $\mathrm{X}$ value that is due to the mesh. Mesh independency is obtained when the relative error is below $5 \%$.
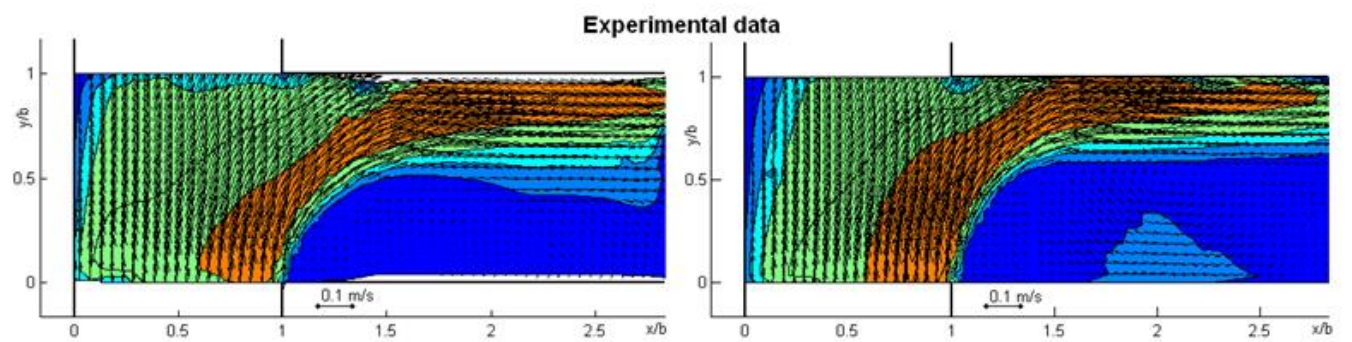
RSM model and scalable wall function
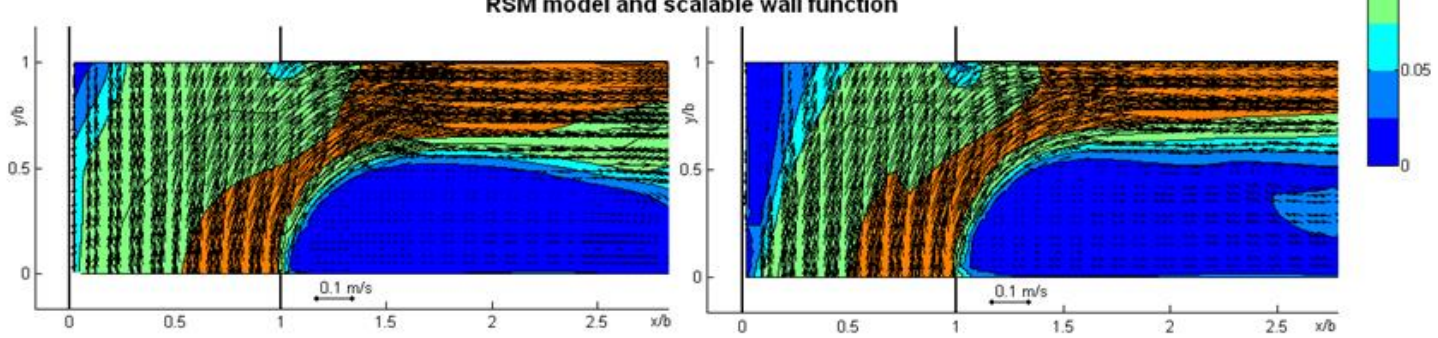

105

Figure 2. Confrontation between PIV measurements of horizontal velocity fields (top) and simulated horizontal velocity fields (bottom) for two elevation: $\mathrm{z}=4 \mathrm{~cm}$ (left) and $\mathrm{z}=9 \mathrm{~cm}$ (right).

\section{Flow structure description}

Table 2. Cases F1 and F2 studied experimentally and numerically exhibiting respectively a "helix-shaped" recirculation and a "closed" recirculation structure in the lateral branch.

\begin{tabular}{cccccc}
\cline { 2 - 5 } Flow id. & $\begin{array}{c}\text { Inlet discharge } \\
Q_{U}\left({\left.\mathrm{~L} . \mathrm{S}^{-1}\right)}\right)\end{array}$ & $\begin{array}{c}\text { Weir } \\
\text { crest } \\
\text { height } \\
h_{\text {crest }}(\mathrm{m})\end{array}$ & $\begin{array}{c}\text { Discharge } \\
\text { distribution } \\
\left(Q_{L} / Q_{U}\right)\end{array}$ & $\begin{array}{c}\text { Froude } \\
\text { Number in } \\
\text { upstream } \\
\text { channel }(-)\end{array}$ & $\begin{array}{c}\text { Upstream aspect } \\
\text { ratio } B / h_{U}(-)\end{array}$ \\
\hline \hline F1 & 8 & 0.09 & 0.47 & 0.218 & 2.50 \\
F2 & 4 & 0.025 & 0.50 & 0.448 & 6.69 \\
\hline \hline
\end{tabular}




\begin{tabular}{ccccc} 
& \multicolumn{4}{c}{$\mathrm{F} 1-h_{\text {crest }}=9 \mathrm{~cm} Q_{U}=8 \mathrm{~L} / \mathrm{s}-$} \\
\cline { 2 - 5 } & Base mesh & $\mathrm{GCl}$ mesh & Absolute mesh error & Relative mesh error \\
\hline \hline Mesh size (cells) & 738000 & 461500 & - & - \\
$Q_{D}\left(\mathrm{~m}^{3} . \mathrm{s}^{-1}\right)$ & 4.320 & 4.352 & 0.053 & 0.012 \\
$Q_{L}\left(\mathrm{~m}^{3} . \mathrm{s}^{-1}\right)$ & 3.743 & 3.706 & 0.061 & 0.016 \\
$U_{\text {moy }-U}\left(\mathrm{~m} . \mathrm{s}^{-1}\right)$ & 0.237 & 0.24 & 0.005 & 0.021 \\
$U_{\text {moy-L } L}\left(\mathrm{~m} . \mathrm{s}^{-1}\right)$ & 0.1104 & 0.1108 & 0.001 & 0.006 \\
\hline \hline
\end{tabular}

$\mathrm{F} 2-h_{\text {crest }}=2.5 \mathrm{~cm} Q_{U}=4 \mathrm{~L} / \mathrm{s}-$

\begin{tabular}{ccccc}
\hline \hline & Base mesh & GCl mesh & Absolute mesh error & Relative mesh error \\
\hline \hline Mesh size (cells) & 756000 & 412500 & - & - \\
$Q_{D}\left(\mathrm{~m}^{3} . \mathrm{s}^{-1}\right)$ & 2.276 & 2.343 & 0.110 & 0.048 \\
$Q_{L}\left(\mathrm{~m}^{3} . \mathrm{s}^{-1}\right)$ & 1.762 & 1.744 & 0.030 & 0.017 \\
$U_{\text {moy-U }}\left(\mathrm{m} . \mathrm{s}^{-1}\right)$ & 0.388 & 0.379 & 0.015 & 0.038 \\
$U_{\text {moy-L }}\left(\mathrm{m} . \mathrm{s}^{-1}\right)$ & 0.211 & 0.21 & 0.002 & 0.008 \\
\hline \hline
\end{tabular}

115

116

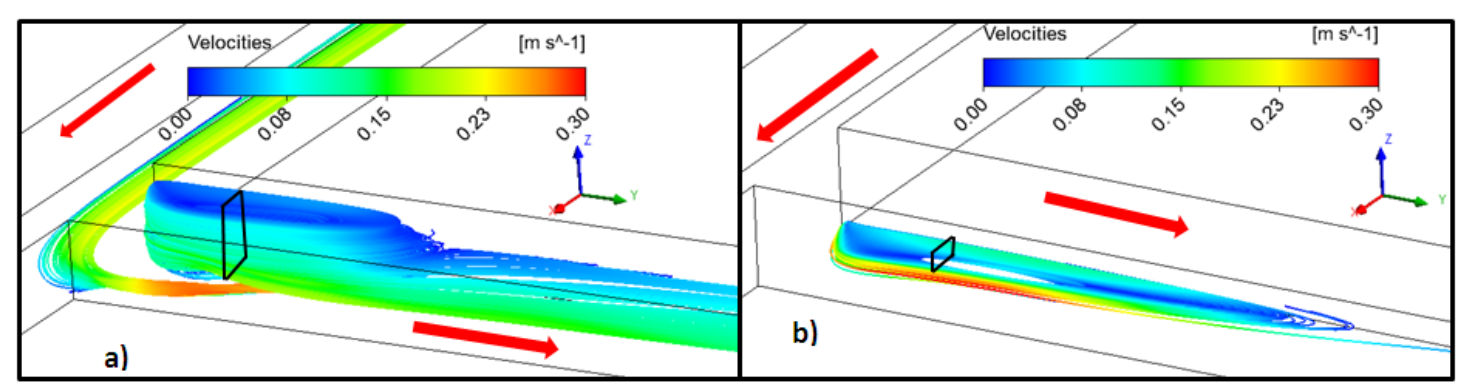

Figure 3. Two flow structures in the lateral branch of a bifurcation flow: a) a helix-shaped recirculation for flow F1 and, b) a closed recirculation for F2. Drawn streamlines are the ones going through the white plane located in the lateral branch at a distance equal to $1 \mathrm{~B}$ from the entry section, covering the whole water depth and extending transversally from the left bank to the streamlines that separates at the corner between the upstream and lateral branches. This plane permits to enclose the whole recirculation. Red arrows indicate the main flow directions. 


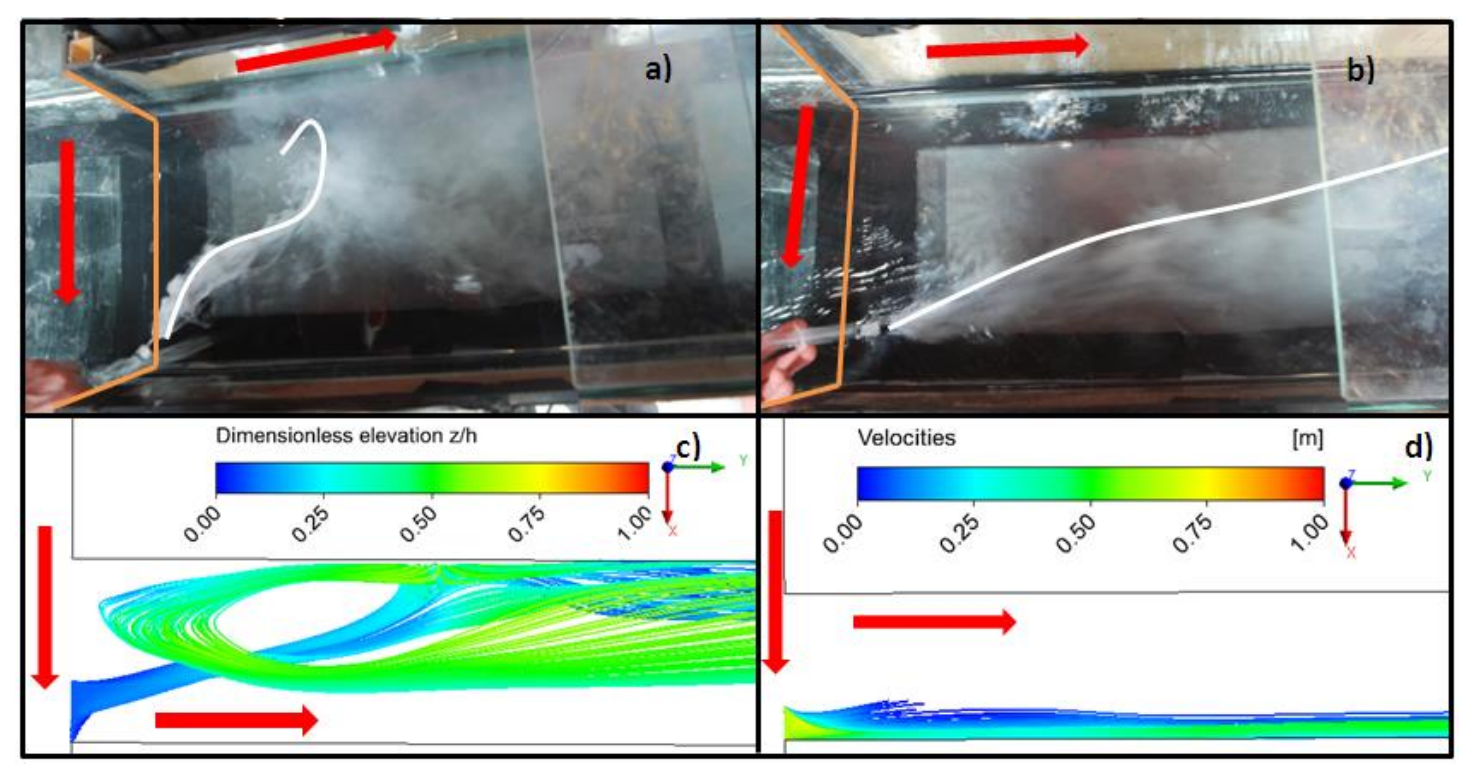

Figure 4. Laboratory and simulation observations of two different flow structures in the lateral branch of two bifurcation flows: F1 (a-c) and F2 (b-d). (a-b) show experiments, (c-d) show numerical streamlines colored by the dimensionless elevation $z / h_{L}$ (from blue, being the bottom of the channel; to red, being the free-surface). For (a-b), a white dye tracer is injected in the downstream corner of the lateral channel, near the bottom, the white line represents the limit of the tracer extension, red arrows indicate flow directions and orange lines mark the inlet section of the lateral branch.

Among all studied flows, two recirculation structures could be observed. Table 2 presents two flow cases investigated numerically and experimentally, each one exhibits a different recirculation structure: a so-called "helix shaped" for F1 and a "closed" one for F2. Fig. 4 shows numerical results for these flow cases and particularly the behaviour of some selected streamlines. Fig. 4 compares experimental observations for the two flow cases regarding the transport of white dye tracer in the lateral branch and numerical streamlines obtained through RANS simulations. In both cases, injection takes place near the bottom part of the downstream corner region. These results confirm the fair agreement between simulated and measured flow patterns. Additionally, results of the GCI analysis displayed in Table 3 indicates that meshes used to compute both flows are efficient for the prediction of discharge and bulk velocities in the lateral branch. Surprisingly, the mesh for flow F2 is less efficient for discharge and velocities representation in the upstream branch than the mesh for flow F1.

The two figures permit to describe both recirculation structures:

- The closed recirculation observed for flow F2 is a 2D semi-elliptic closed region developing along the upstream wall of the lateral branch as described in the literature: no flow enters or leaves this region and it is of larger streamwise and transverse extension at the freesurface than near the bed (Fig. 3b). Consequently, the streamlines starting from the 
150 downstream corner of the intersection remain quite parallel to the banks of the lateral channel 151 towards downstream and do not interact with the recirculation zone (Fig. 4b).

152 - The helix-shaped recirculation observed for flow F1 is a 3D ascendant flow (see Fig.

153 3a and 4c): i. supplied by the bottom flow of the upstream channel, ii. entering the lateral

154 branch near the bottom part of the downstream corner area, iii. approaching the opposite

155 (upstream) wall of the lateral branch, iv. raising towards the free-surface, first in the direction

156 of the intersection (towards upstream) and then towards downstream along center of the

157 branch. v. escaping towards downstream in the upstream half of the branch. Consequently, the

158 streamlines starting from the downstream corner of the intersection enter the recirculation

159 structure (Fig. 4a). These two distinct flow structures corroborate the different streamlines

160 plots near the bottom reported by Neary et al. (1999) in their figure 10 and the pathlines in

161 their figure 11c.

\section{Flow typology}

163 In order to establish the flow conditions for which each recirculation structure is observed, a

164 flow typology is established following the parameters obtained through dimensional analysis.

165 Using the same approach as Mignot et al. (2013) and assuming (as for the authors) that the

166 flow is turbulent (see Table 10) and smooth, the 8 parameters governing the flow

167 characteristics are: the three discharges $\left(Q_{U}, Q_{L}, Q_{D}\right)$, the three water depths $\left(h_{U}, h_{L}, h_{D}\right)$ and

168 the two weir crest heights $\left(C_{D}, C_{L}\right)$. Mass conservation equation $\left(Q_{U}=Q_{L}+Q_{D}\right)$ permits to

169 remove one parameter $\left(Q_{L}\right)$; both known stage discharge equations $\left(h_{D}=\mathrm{f}\left(Q_{D}, C_{D}\right)\right.$ and $h_{L}=$

$\left.170 \mathrm{f}\left(Q_{L}, C_{L}\right)\right)$ permit to remove $h_{L}$ and $C_{D}$; the momentum equation introduced by Ramamurthy $e t$

171 al. (1990) permits to remove $h_{D}$; the empirical closure equation introduced by Rivière et al.

172 (2007) permits to remove $Q_{D}$; finally, the following simplification considered in the present

173 work $C_{D}=C_{L}$ permits to remove $C_{L}$. We end up with the two remaining parameters $Q_{U}$ and $h_{U}$,

174 which can be transformed (see Mignot et al., 2013) as dimensionless independent parameters:

175 upstream Froude number $F r_{U}$ and upstream aspect ratio $B / h_{U}$. Note that the present

176 simplification $C_{D}=C_{L}$ is responsible for the reduction of independent parameters from 3 in

177 Mignot et al. (2013) to 2 in the present work and leads to a discharge distribution $Q_{U} / Q_{U}$ of 178 about 45 to $55 \%$.

179 The aim of the part being a flow typology assessment for a recirculation zone, a quick

180 look at others recirculation zone typologies is needed. There is many situations leading to a

181 recirculation zone (listed by $\mathrm{Li}$ and Djilali, 1995). For each of these situations, a flow

182 typology can be established by studying specific forces configurations. For example, Chu et

183 al. (2004) establish a typology for a recirculation zone where confinement and friction are the 184 determining forces. Dufresne et al. (2010) also establish a recirculation zone typology in 185 rectangular shallow reservoirs, where inertial forces and pressure/water depth gradients are 
determining forces. These two cases lead to two different typologies. In the present case, the suspected determining forces are centrifugal force and pressure force: when the centrifugal force effect is significant, we can observe the helix-shaped recirculation because of the pressure force induce by the centrifugal force (see Fig. 5). It is similar to the tea-leaves effect.
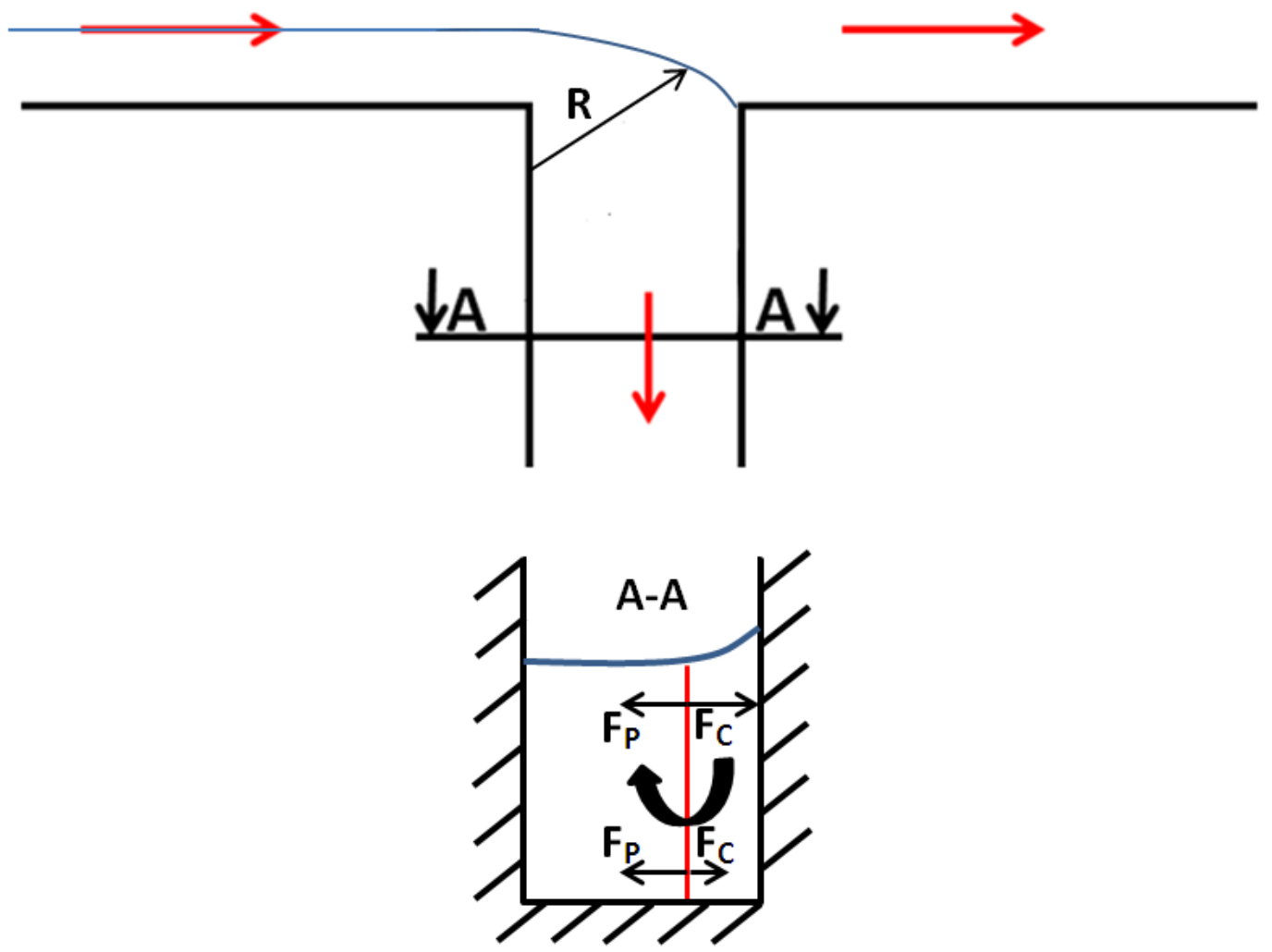

Figure 5. Forces balance in a lateral branch cross-section. Red arrows indicate flow directions. $F_{C}$ is the volume centrifugal force $\left(\mathrm{N} . \mathrm{m}^{-3}\right), F_{P}$ the volume pressure force $\left(\mathrm{N} . \mathrm{m}^{-3}\right)$. Blue line indicates the free surface in the cross-section and $R$ is the curvature radius of the separation.

Two forces are defined in the lateral branch cross-section A-A (see Fig. 5) as follow:

$$
F_{C}=\rho \frac{U_{U}^{2}}{R}
$$

Equation 2

$$
F_{P}=\rho g
$$

Equation 3
Where:
$-F_{C}$ : the centrifugal force $\left(\mathrm{N} . \mathrm{m}^{-3}\right)$
$-U_{U}$ : the mean velocity in the upstream channel $\left(\mathrm{m} . \mathrm{s}^{-1}\right)$
$-R$ : the curvature radius of the separation (m)
$-F_{P}$ : the pressure force $\left(\mathrm{N} . \mathrm{m}^{3}\right)$
$-g$ : the acceleration of gravity $\left(=9.81 \mathrm{~m} \cdot \mathrm{s}^{-2}\right)$ 
A comparison between the two defined forces gives:

$$
\frac{F_{C}}{F_{P}}=\frac{\rho \frac{U_{U}^{2}}{R}}{\rho g}=\frac{U_{U}^{2}}{R g}
$$

It is possible to assimilate $R$ to the channel width $B$. Equation 4 becomes:

$$
\frac{F_{C}}{F_{P}}=\frac{U_{U}^{2}}{B g}=\frac{U_{U}^{2}}{\frac{B}{h_{U}} \cdot g h_{U}}=\frac{F r_{U}^{2}}{\frac{B}{h_{U}}}
$$

With:

$-h_{U}$ : the water depth in the upstream channel (m)

Equation 5 indicates that a relationship between the squared Froude number in the upstream channel $\mathrm{FrU}^{2}$ and the upstream aspect ratio $\mathrm{B} / \mathrm{hU}$ can determine the flow topology. A numerical campaign is led to investigate this possible relationship.

Table 4 presents the numerical campaign, comprising 16 flow cases, led to establish the flow typology. For each case, Froude number is upstream channel $F r_{U}$ is defined as:

$$
F r_{U}=\frac{U_{U}}{\sqrt{g \cdot h_{U}}} \in[0.035 ; 0.558]
$$

Reynolds number in upstream channel $\mathrm{ReU}$ is defined as:

$$
R e_{U}=\frac{4 \cdot U_{u} \cdot B \cdot h_{U}}{v \cdot\left(B+2 \cdot h_{U}\right)} \in[7400 ; 103900]
$$

With : $\quad-U_{U}$ : the mean velocity in the upstream channel $\left(\mathrm{m} \cdot \mathrm{s}^{-1}\right)$

$$
\begin{aligned}
& -B \text { : the channel width }(\mathrm{m}) \\
& -h_{U} \text { : the upstream channel water depth }(\mathrm{m})
\end{aligned}
$$

All tested cases are thus subcritical and turbulent (see Table 4).

For this campaign, the crest height in both outlet branches $C_{D}$ and $C_{L}\left(C_{D}=C_{L}\right)$ and the upstream discharge $Q_{U}$ are the two varying boundary conditions which permit to vary the

Table 4. Simulated cases for the typology numerical campaign.

\begin{tabular}{ccccccc} 
& $\begin{array}{c}\text { Crest height in } \\
\text { downstream } \\
\text { branches } h_{\text {crest }} \\
(\mathrm{m})\end{array}$ & $\begin{array}{c}\text { Inlet } \\
\text { discharge } \\
Q_{U}\left({\left.\mathrm{~L} . \mathrm{s}^{-1}\right)}\right.\end{array}$ & $\begin{array}{c}\text { Flow } \\
\text { distribution } \\
\left(Q_{L} / Q_{U}\right)\end{array}$ & $\begin{array}{c}\text { Reynolds } \\
\text { Number in } \\
\text { upstream } \\
\text { branch } \operatorname{Re}_{U}(-)\end{array}$ & $\begin{array}{c}\text { Froude Number } \\
\text { in upstream } \\
\text { branch Fru }(-)\end{array}$ & $\begin{array}{c}\text { Upstream } \\
\text { aspect ratio } \\
B / h_{U}(-)\end{array}$ \\
\hline \hline Case 1 & 0.03 & 1 & 0.485 & 11066 & 0.204 & 10.00 \\
Case 2 & 0.03 & 4 & 0.45 & 40240 & 0.400 & 6.20 \\
Case 3 & 0.03 & 8 & 0.454 & 75340 & 0.540 & 4.76 \\
Case 4 & 0.03 & 12 & 0.345 & 88130 & 0.558 & 4.29 \\
Case 5 & 0.05 & 1 & 0.505 & 9700 & 0.095 & 6.12 \\
Case 6 & 0.05 & 4 & 0.481 & 39810 & 0.260 & 4.41
\end{tabular}




\begin{tabular}{llccccc} 
Case 7 & 0.05 & 8 & 0.457 & 79070 & 0.333 & 3.84 \\
Case 8 & 0.05 & 12 & 0.433 & 103903 & 0.486 & 3.30 \\
Case 9 & 0.07 & 1 & 0.511 & 8504 & 0.052 & 4.16 \\
Case 10 & 0.07 & 4 & 0.472 & 35950 & 0.172 & 3.37 \\
Case 11 & 0.07 & 8 & 0.459 & 67260 & 0.289 & 3.06 \\
Case 12 & 0.07 & 12 & 0.555 & 80810 & 0.352 & 2.75 \\
Case 13 & 0.09 & 1 & 0.521 & 7400 & 0.035 & 3.33 \\
Case 14 & 0.09 & 4 & 0.488 & 34310 & 0.130 & 2.73 \\
Case 15 & 0.09 & 8 & 0.468 & 63070 & 0.218 & 2.50 \\
Case 16 & 0.09 & 12 & 0.474 & 96800 & 0.266 & 2.00 \\
\hline \hline
\end{tabular}

Fig. 6 shows the distribution of each recirculation structure, according to two parameters: squared upstream Froude number $F r_{U}^{2}$ and upstream aspect ratio $B / h_{U}$. Both regions are 234 clearly separated from each other: a linear - at least with the present set of experiments 235 oblique boundary separates the two types. For low $F r_{U}{ }^{2}$ and high $B / h_{U}$ values, the closed recirculation takes place whilst for high $F r_{U}^{2}$ and low $B / h_{U}$ values, the helix-shaped recirculation occurs

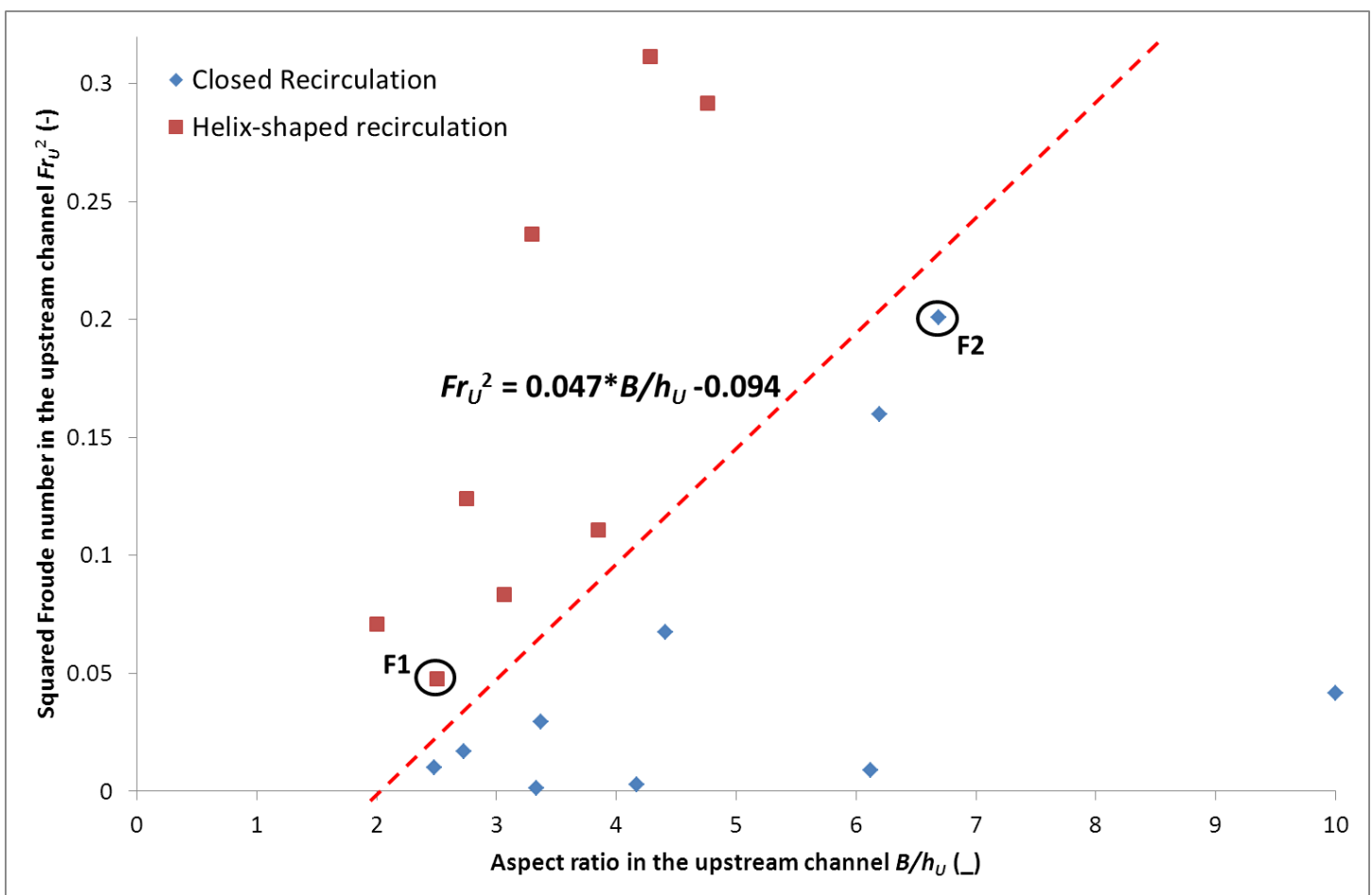

Figure 6. Flow typology in the lateral branch. Flow F1 and F2 are circled. The red-dashed line

240 represents the boundary between a classic recirculation in lateral branch and a helix-shaped 241 one.

\section{Conclusions and perspectives}

243 The present papers aimed at defining the flow patterns occurring in the lateral branch of an 244 open-channel bifurcation. A typology comprising two flow structures was established based 
on the characteristics of the recirculation zone. The two structures are named i. "closed

246 recirculation", similar to the flow pattern previously described in the literature and ii. "helix-

247 shaped recirculation" for which the flow pattern strongly differs and is described in the

248 present paper. Both structures were observed using both experimental and numerical

249 approaches. Following the assumptions of a smooth and turbulent flow regime and equal weir

250 crest heights at both outlets, the typology is based on the comparison between centrifugal

251 force effect and pressure force effect by the mean of squared upstream Froude number $F r_{U}^{2}$

252 and upstream aspect ratio $B / h_{U}$ and exhibits two clear regions of recirculation structure

253 occurrence.

254 As perspectives, bed friction effect should be investigated, as well as Reynolds number effect.

255 As the define flow topology depends on curvature radius of the separation, the effect of

256 channel width ratio and discharge repartition will have an effect and should also be

257 investigated.

258 Acknowledgements

259 These works are part of the laboratory of excellence IMU (Smartness on Urban Worlds) and

260 the OTHU (Field Observatory for Urban Hydrology) at Lyon. Authors would like to thank:

261 the French ministry of research for the Ph.D. funding and the ANR (National Agency for

262 research) project funding (ANR-11-ECOTECH-007-MENTOR) and the INSU (National

263 Institute for Universe Science, project EC2CO-Cytrix 2011 project No 231).

\section{Notations}

$265 \quad B=$ channel width (m)

$266 C_{L}=$ crest height in the lateral branch (m)

$267 C_{D}=$ crest height in the downstream branch (m)

$268 F_{C}=$ centrifugal force $\left(\mathrm{N} \cdot \mathrm{m}^{-3}\right)$

$269 \quad F_{P}=$ pressure force $\left(\mathrm{N} . \mathrm{m}^{-3}\right)$

$270 \quad F r_{U}=$ Froude number in upstream channel (-)

$271 G C I_{X}=$ grid convergence index value for variable $X$ (dimension of variable $X$ )

$272 h_{U}=$ water depth in the upstream channel $(\mathrm{m})$

$273 h_{L}=$ water depth in the lateral branch $(\mathrm{m})$

$274 h_{D}=$ water depth in the downstream branch $(\mathrm{m})$

$275 h_{\text {crest }}=$ crest height for case F1 and F2 (m)

$276 k=$ wall roughness $(\mathrm{m})$

$277 \quad N_{C}=$ number of cells of the coarse mesh (-)

$278 \quad N_{F}=$ number of cells of the fine mesh (-)

$279 P_{0}=$ atmospheric pressure $(\mathrm{Pa})$

$280 Q_{U}=$ upstream discharge $\left(\mathrm{L} . \mathrm{s}^{-1}\right)$

$281 Q_{L}=$ lateral branch discharge $\left(\mathrm{L} . \mathrm{s}^{-1}\right)$

$282 Q_{D}=$ downstream branch discharge $\left(\mathrm{L} . \mathrm{s}^{-1}\right)$

$283 r=$ cell number ratio between fine mesh and coarse mesh (-)

$284 R=$ curvature radius of the separation zone $(\mathrm{m})$

$285 R e_{U}=$ Reynolds number in upstream branch (-) 
$U_{\text {Inlet }}=$ numerical velocity set at the inlet cross-section of the upstream channel $\left(\mathrm{m} \cdot \mathrm{s}^{-1}\right)$

$U_{U}=$ mean velocity in the upstream channel $\left(\mathrm{m} \cdot \mathrm{s}^{-1}\right)$

$X_{C}=$ value of variable $X$ for coarse mesh (variable)

$X_{F}=$ value of variable $\mathrm{X}$ for fine mesh (variable)

$z=$ elevation $(\mathrm{m})$

$v=$ viscosity of water $\left(=1.10^{-6} \mathrm{~m}^{2} \cdot \mathrm{s}^{-1}\right)$

\section{References}

Chu, V. H., Liu, F., \& Altai, W. (2004). Friction and confinement effects on a shallow recirculating flow. Journal of Environmental Engineering and Science, 3(5), 463-475.

Dufresne, M., Dewals, B. J., Erpicum, S., Archambeau, P., \& Pirotton, M. (2010). Experimental investigation of flow pattern and sediment deposition in rectangular shallow reservoirs. International Journal of Sediment Research, 25(3), 258-270.

Grace, J. L. \& Priest, M. S. (1958). Division of flow in open channel junctions. Bulletin No.31. Engineering Experiment Station, Alabama Polytechnic Institute.

Grotjans H. \& Menter F. R. 1998. Wall functions for industrial applications. In Proceedings of Computational FluidDynamics'98, ECCOMAS, 1(2), Papailiou KD (ed.). Wiley: Chichester, U.K.. 1112-1117

Hsu, C. C., Tang, C. J., Lee, W. J. \& Shieh, M. Y. (2002). Subcritical 90 equal-width openchannel dividing flow. Journal of Hydraulic Engineering, 128(7), 716-720.

Kasthuri B. \& Pundarikanthan N. V. (1987). Discussion of "Separation zone at open channel junctions". Journal of Hydraulic Engineering, 113(4), 543.

Launder B. E., Reece G. J. \& Rodi W. (1975). Progress in the Development of a ReynoldsStress Turbulence Closure. Journal of Fluid Mechanics. 68(3). 537-566

Li X. \& Djilali N. (1995). On the scaling of separation bubbles. JSME international journal. Series B, fluids and thermal engineering, 38(4), 541-548.Mignot, E., Zeng, C., Dominguez, G., Li, C. W., Rivière, N. \& Bazin, P. H. (2013). Impact of topographic obstacles on the discharge distribution in open-channel bifurcations. Journal of Hydrology, 494, 10-19.

Mignot, E., Doppler, D., Riviere, N., Vinkovic, I., Gence, J. N. \& Simoens, S. (2014). Analysis of flow separation using a local frame-axis: application to the open-channel bifurcation. Journal of Hydraulic Engineering. 280-290.

Momplot, A., Lipeme Kouyi, G., Mignot, E., Rivière, N. \& Bertrand-Krajewski, J.-L. (2013) URANS Approach for Open Channel Bifurcation Flows Modelling. 7th International Conference on Sewer Processes and Network, Sheffield, August 2013, 8 pages.

Neary, V. S., Sotiropoulos, F. \& Odgaard A. J. (1999). Three-dimensional numerical model of lateral intake inflows. Journal of Hydraulic Engineering, 125(2), 126-140. 
Ramamurthy, A. S., Tran, D. M. \& Carballada, L. B. (1990). Dividing flow in open channels. Journal of Hydraulic Engineering, 116(3), 449-455.

Ramamurthy, A. S., Qu, J. \& Vo, D. (2007). Numerical and experimental study of dividing open-channel flows. Journal of Hydraulic Engineering, 133(10), 1135-1144.

326 Rivière, N., Travin, G. \& Perkins R. J. (2007). Transcritical flows in open channels junctions. Proceedings, $32^{\text {nd }}$ IAHR Congress, Venice, Italy, IAHR, paper SS05-11.

Rivière, N., G. Travin, and R. J. Perkins (2011), Subcritical open channel flows in four branch intersections, Water Resour. Res., 47, W10517, doi:10.1029/2011WR010504.

Shettar, A. S. \& Keshava Murthy, K. (1996). A numerical study of division of flow in open channels. Journal of Hydraulic Research, 34(5), 651-675. 